\section{Signaling Inclusivity in Undergraduate Biology Courses through Deliberate Framing of Genetics Topics Relevant to Gender Identity, Disability, and Race}

Karen G. Hales*

Department of Biology, Davidson College, Davidson, NC 28035

\begin{abstract}
The study of genetics centers on how encoded information in DNA underlies similarities and differences between individuals and how traits are inherited. Genetics topics covered in a wide variety of undergraduate biology classrooms can relate to various identities held by students such as gender identity, disability, and race/ethnicity, among others. An instructor's sensitive approaches and deliberate language choices regarding these topics has the potential to make the critical difference between welcoming or alienating students and can set a tone that communicates to all students the importance of diversity. Separating the sperm/egg binary from gendered terms in coverage of inheritance patterns, along with inclusion of transgender people in pedigree charts, may make the classroom more welcoming for students of diverse gender identities. Choosing nonstigmatizing language and acknowledging disability identities in discussions of genetic conditions may help students with visible and invisible disabilities feel validated. Counteracting genetics-based pseudoscientific racism and the stereotype threat to which it contributes may be facilitated by more thorough integration of quantitative and population genetics topics. Instructors may thus potentially enhance retention of students of diverse backgrounds in biology through careful consideration and crafting of how human differences are described and connected with principles of genetics.
\end{abstract}

\section{INTRODUCTION}

Efforts toward more inclusive pedagogy in the undergraduate science classroom have focused largely on ideas applicable to nearly any course regardless of topic. Examples include initiatives to eliminate microaggressions that exacerbate stereotype threat, increase microaffirmations to counteract such threat, highlight research findings from diverse scientists, use classroom examples representing varied identities, and structure activities and dialogue to foster comfortable participation by all students (Tanner, 2013; Seidel et al., 2015; Schinske et al., 2016; Harrison and Tanner, 2018; Dewsbury and Brame, 2019; Estrada et al., 2019). When classroom topics relate to people's identities, subject-specific inclusive approaches and language choices are also merited. Undergraduate genetics courses typically cover mechanisms across a wide variety of organisms, though often with a focus on mammalian/human processes, because students (especially those aiming for medical professions) find human topics particularly engaging. Genetics topics related to humans and their differences can potentially set the stage for content-related microaggressions and alienation, depending on the manner in which the material is presented. For example, cisgender-normative and heteronormative depictions of inheritance patterns can invalidate differences in gender identity and sexual orientation. In addition, certain terminology concerning variant phenotypes can be alienating to those with disabilities by implying a narrow, ableist view of "normality." The persistence of pseudoscientific racism from before the
Rebecca Price, Monitoring Editor Submitted Aug 16, 2019; Revised Mar 2, 2020; Accepted Mar 6, 2020

CBE Life Sci Educ June 1, 2020 19:es2

DOI:10.1187/cbe.19-08-0156

*Address correspondence to: Karen G. Hales (kahales@davidson.edu).

(c) 2020 K. G. Hales. CBE-Life Sciences Education (c) 2020 The American Society for Cell Biology. This article is distributed by The American Society for Cell Biology under license from the author(s). It is available to the public under an Attribution-Noncommercial-Share Alike 3.0 Unported Creative Commons License (http://creativecommons.org/ licenses/by-nc-sa/3.0).

"ASCB®" and "The American Society for Cell Biology ${ }^{\circledR}$ " are registered trademarks of The American Society for Cell Biology. 


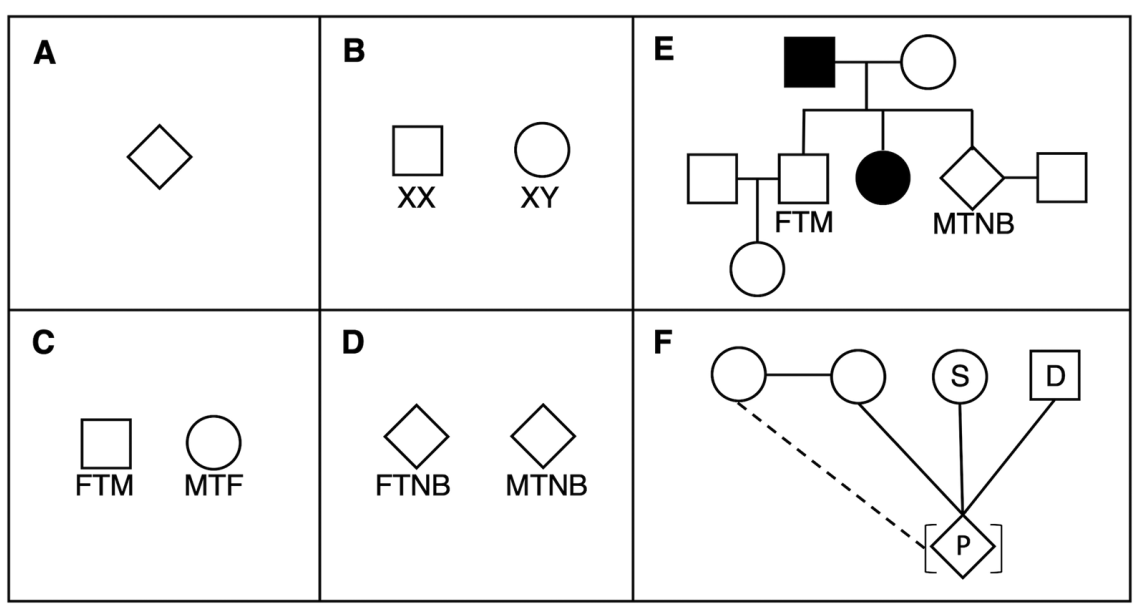

FIGURE 1. Approaches for depicting trans people and various reproductive arrangements in pedigree charts. The National Society of Genetic Counselors' official method for depicting a trans person in pedigree charts (Bennett et al., 2008) is a diamond (A) or else (B) a circle/square corresponding to "phenotypic" gender (gender identity) with karyotype when known. A nonofficial, more inclusive approach for classroom use is a circle/square corresponding to binary gender identity (C) or a diamond for nonbinary identity (D), in either case with an abbreviation that indicates gender assigned at birth; this method validates gender identity, does not depend on the availability of a karyotype, and provides information on whether the person is potentially a sperm parent or egg parent. FTM, female to male; MTF, male to female; FTNB, female to nonbinary; MTNB, male to nonbinary. (E) Example of a pedigree including trans individuals, showing inheritance of an unrelated autosomal dominant trait (filled-in symbols). (F) Example of a pedigree showing surrogacy, gamete donation, and adoption, using symbols and terminology standardized by the National Society of Genetic Counselors (Bennett et al., 2008). From a couple (connected by horizontal line), one person's egg is fertilized by sperm from a donor (square with $\mathrm{a} D$ ). A woman is contracted to be a surrogate (circle with an S) to carry the pregnancy (diamond with a P) to term. The member of the couple who is not biologically related to the offspring is an adoptive parent (dashed line and brackets).

eugenics movement to the present demands explicit countervalence in the form of precise language on human differences/ similarities and the multifaceted basis of complex traits. The recent availability and misinterpretation of direct-to-consumer genetic ancestry testing (Lawton and Ifama, 2018) accentuates this need. I discuss here approaches and language choices for biology instructors to foster inclusion across the dimensions of gender identity, disability, and race when discussing genetics-related topics at various levels of the undergraduate curriculum.

\section{SEPARATING THE GENDER IDENTITY SPECTRUM FROM THE SPERM-EGG BINARY IN DEPICTING AND DESCRIBING INHERITANCE OF TRAITS \\ Representation of Diverse Gender Identities in Pedigree Charts}

Geneticists frequently use pedigree charts to depict and analyze inheritance of traits in a family. In undergraduate genetics textbooks (Pierce, 2016; Brooker, 2017; Hartl and Cochrane, 2017; Hartwell et al., 2017; Lewis, 2017), the definition of pedigree symbols is that circles represent females, squares represent males, and diamonds represent a person of "unspecified" gender. Using the diamond symbol only for cases of "unspecified" gender implies that the person must still conform to a malefemale binary but in an unknown manner. The "female" symbols are presumed to represent egg producers, and "male" symbols are presumed to represent sperm producers. This setup may result in microinvalidations (a type of microaggression; Harrison and Tanner, 2018) of transgender people. The adjective "transgender," hereafter abbreviated as "trans," encompasses people with a male or female identity different from that assigned at birth, as well as those who are nonbinary, identifying as neither male or female or as both along a spectrum (Kapitan, 2017).

Pedigree charts are essential to the work of genetic counselors and physicians who evaluate, advise, and treat patients and their families regarding genetic conditions and future probability of transmission. The Pedigree Standardization Work Group (PSWG) within the National Society of Genetic Counselors established a standard format for pedigree charts in 1995 with refinements in 2008 (Bennett et al., 1995, 2008). Transgender individuals are to be depicted as a diamond (Figure 1A) or sometimes with a circle or square corresponding to "phenotypic gender" (gender identity when either male or female) with karyotype when known (Figure 1B). In the clinic, genetic counselors and physicians are typically the sole small audience for the pedigree charts they create; from their perspective, a diamond is better than a circle or square to trigger the clinician to explore aspects of reproductive health with a trans patient, for example, ovarian cancer in a BRCA1 carrier who is a trans man (R. Bennett, personal communication). In the classroom, however, diamond symbols do not accurately correspond to gender identity for binary trans individuals and thus may be perceived as a microinvalidation. Members of the PSWG have considered but not codified another possible format (Figure 1C) that depicts a binary trans person with the symbol corresponding to gender identity, along with "FTM" or "MTF" notation to indicate female to male or male to female, respectively (R. Bennett, personal communication). This method validates gender identity while simultaneously providing information on physiology, which is often relevant in pedigree analysis, given different contributions of sperm and egg (discussed later).

In my classes, I employ this noncodified pedigree format for indicating binary trans people with a circle or square corresponding to gender identity and an abbreviation indicating gender assigned at birth (Figure 1C), even though it is not the accepted standard among genetic counselors. I further extend this system to use a diamond symbol for nonbinary people along with "MTNB" or FTNB" notation (for male to nonbinary, or female to nonbinary, respectively; Figure 1D). I am explicit with my students about my intentional divergence from PSWG standards, acknowledging that my goal is to acknowledge gender identity as central yet separable from the binary of spermegg production. 
One of many strategies for inclusive pedagogy is incorporating classroom examples that encompass diversity and that allow all students to see themselves represented (Case et al., 2009; Tanner, 2013). Including trans people as family members in classroom pedigree examples has the potential to foster a sense of belonging among students who share those identities as well as among cisgender students with trans family and friends. Until such examples begin appearing in textbooks, genetics instructors are encouraged to create their own adaptations of pedigree examples to achieve these aims, as in Figure 1E. Such inclusion may also be helpful to students who have less familiarity with this type of diversity. More broadly, depiction of LGBTQIA+ couples in pedigrees achieves analogous goals for people across the spectra of not only gender identity but also sexual orientation. The PSWG pedigree standards provide ways to symbolize adoptions, surrogacy, and egg and sperm donors for families in which these arrangements occur (Figure 1F; Bennett et al., 1995, 2008).

\section{Inclusive Language Regarding Body Parts, Sperm, Eggs, Chromosomes, and Gender Identity}

Best practices to foster classroom inclusivity for trans students often emphasize, among many other things, the necessity to "decouple anatomy from identity" (Kapitan, 2017) and to avoid "compulsory gendered assignment of body parts" (Spade, 2011). People with ovaries, uteruses, vulvas, and/or vaginas can identify as male, female, or nonbinary along a spectrum. Likewise, people with penises and testicles can have widely varying gender identities. Some people born with various combinations of sex organs and sex chromosomes who are assigned as intersex at birth may later identify anywhere along the same spectrum. It is imprecise and indeed invalidating to trans people to define any specific anatomical feature as "male" or "female" (Spade, 2011). Instead, the terms for individual body parts can be used directly, or if collective terms for sets of features are needed, perhaps "sperm-producing and sperm-conducting organs" or "egg-conducting tissues and gestational organs" can be considered (Table 1).

In reference to the whole person, the phrases "biologically female" or "biologically male" (based on internal and/or external reproductive organs) are imprecise, because brain wiring

TABLE 1. Suggestions for terminology to separate body parts, sperm, eggs, and chromosomes from gendered language

\begin{tabular}{lc}
\hline $\begin{array}{l}\text { Commonly used term } \\
\text { or phrase }\end{array}$ & \multicolumn{1}{c}{ Suggested alternatives } \\
\hline Female anatomy/organs & $\begin{array}{c}\text { Egg-conducting and gestational organs } \\
\text { (or use specific body part names) } \\
\text { Male anatomy/organs } \\
\text { Sperm-producing and } \\
\text { sperm-conducting organs } \\
\text { (or use specific body part names) } \\
\text { Assigned female } \\
\text { Person born with ovaries, uterus, } \\
\text { vagina, vulva, etc. }\end{array}$ \\
Biologically male & $\begin{array}{c}\text { Assigned male } \\
\text { Person born with penis, testicles, etc. }\end{array}$ \\
Mother or biological mother & $\begin{array}{l}\text { Egg parent } \\
\text { Father or biological father }\end{array}$ \\
Sperm parent
\end{tabular}

underlying gender identity is similarly biological. The terms "assigned female" or "assigned male" are preferred (Table 1; Spade, 2011). The phrase "person born with [body part]" may be suitable, though the phrase "born with" is crucial to account for the possibility of surgery in the meantime. Furthermore, when discussing sex chromosomes in humans, genetics instructors are encouraged avoid oversimplification, making it clear that XX and XY karyotypes (along with $\mathrm{XO}, \mathrm{XXY}$, and other sex chromosome aneusomies) do not necessarily correlate, respectively, to female and male assignments at birth or to female and male gender identity, because of the complexity of the developmental pathways, the multiple possible gene variants involved, and the possibility of mosaicism-the presence of genetically distinct cells (for example XX and XY)—within the same body.

When discussing genetics topics, this need to divest gender from body parts, gametes, and karyotype extends to the descriptions of parental relationships. Given the asymmetric contributions of egg and sperm to the zygote regarding cytoplasmic components such as mitochondria and RNA, as well as imprinted genes, it remains crucial for the sake of precise genetic analysis to distinguish which biological parent contributes which gamete. In recent years I have been shifting my language in the classroom to avoid the gender-loaded terms "mother" and "father" and instead have adopted "egg parent" and "sperm parent" as more precise and inclusive options (Table 1). An "egg parent" can be a trans man who might identify as a father, a cisgender woman who might identify as a mother, a nonbinary person who might not connect with either gendered parental term, or an egg donor who is not a caregiving parent. A recent case of a pregnant trans man losing his baby because of lack of awareness on the part of healthcare professionals at the hospital where he arrived (Stroumsa et al., 2019) highlights the need for a broader linguistic shift. The terms "egg parent" and "sperm parent" precisely distinguish biological contributions from social/caregiving and other parental relationships, including adoption and/or surrogacy. Also, when mitochondrial replacement therapy is used (Kang et al., 2016), the expanded phrases "egg nuclear parent" and "egg cytoplasmic parent" can be incorporated.

The word "parent" is indeed defined in all major dictionaries as referring to a biological and/or social/caregiving relationship, and thus the language I propose is consistent with broadly accepted usage of the word. However, people who prefer to reserve the word "parent" exclusively for a caregiving context might choose an alternative system that eliminates the word "parent" entirely, instead using "egg donor" and "sperm donor" for delineating biological relatedness, regardless of social connections. Such a system would require disambiguation from the commonly accepted uses of "egg donor" and "sperm donor" as referring to gamete harvesting for in vitro use or artificial insemination. My sense is that this more dramatic linguistic shift is less likely to gain traction among genetics instructors, and so I will continue to suggest "egg parent" and "sperm parent" as nongendered clarifications of "biological parent."

Any large-scale shift in the biomedical literature away from gendered description of body parts, gametes, and parental relationships will certainly be slow. However, if we as biology educators separate the egg-sperm binary from gendered language 
in order to affirm and not invalidate diverse gender identities, we can contribute to this gradual shift as our students enter the workforce in biomedicine and other areas.

\section{CHOOSING INCLUSIVE LANGUAGE FOR DESCRIBING HUMAN GENETIC DIFFERENCES CONNECTED TO DISABILITY}

Genetics is intrinsically focused on similarities and differences between individuals at the molecular level, some of which lead to various types of ability and disability in humans. A subset of disabled people have a genetic basis for their disability. Within this intersection are individuals who might find themselves in a biology class where they encounter discussion of disabilities like their own. Disability can be visible or invisible and, broadly defined, can refer to "physical, sensory, psychological, chronic health, neurological, cognitive, or social" traits (Center for Disability Rights, n.d., para. 3). Instructors teaching about genetic conditions and variations who develop cultural competency regarding inclusive language may foster a sense of belonging among disabled students who might perceive that their identities, whether known to others or not, are in the spotlight. Some students with invisible disabilities self-identify to instructors and others do not; thus, an instructor's classroom statements should never imply an assumption that disabled people are not present. By one estimate, 14.6\% of college students identify as having at least one hidden disability (Higher Education Research Institute, 2011). Approximately $19 \%$ of college students have at least one disability of any type, visible or invisible (Snyder et al., 2019). Genetic conditions being discussed could be intimately familiar to any student via their own or a loved one's experience. An instructor's excitement about the topic might unknowingly come across as insensitive or triggering unless tempered by acknowledgment of the connection to real human lives. Showing images of individuals with disabilities may be similarly problematic. Faculty who address directly with students the history of objectification of disabled people (Nielsen, 2012) and who respect the agency of each person while conveying differences have the potential to make the classroom a more inclusive space. Students with disabilities of any kind should never be singled out or pressured to share observations unless they express eagerness to do so of their own volition.

A biological focus usually results in framing genetic conditions with the "medical model," which presumes an imperative to "fix" the disability. In contrast, the "social model" of disability, preferred by many (if not most) in the disability community, centers on the need for societal changes to accommodate everyone (Center for Disability Rights, n.d.). The relationship between these models and people's lived experiences is complex. In reality, some genetic chronic illnesses like sickle cell anemia and cystic fibrosis are contexts in which people typically do indeed desire medical assistance to improve quality of life. Genetics classes often include significant coverage of gene therapy approaches and other molecular treatments and thus are inevitably intertwined with the medicalized framework. Yet these treatments do not preclude disability as an identity and do not inherently imply that disabled lives are defined only by suffering and the need to be "normal." Indeed, many genetic types of disability, such as deafness and dwarfism, are the basis of strong identity and community. It can be an unwelcome invalidation when biology instructors automatically frame such characteristics in a medicalized context, such as when preimplantation genetic diagnosis is described as preventing the birth of such individuals. Genetic testing is not uniformly viewed positively, as assessed among the Deaf community (Taneja et al., 2004). The specter of CRISPR-Cas9 gene editing in human embryos (Cyranoski and Ledford, 2018) adds to the threat felt by some with disability identities. Emphasizing in class that varying outcomes of human development are part of a normal population and do not necessarily need to be "fixed" or cured may mitigate this effect. The disability studies expert Simi Linton states that "medicalization of disability casts human variation as deviance from the norm, as pathological condition, as deficit, and, significantly, as an individual burden and personal tragedy" (Linton, 1998, p. 11). The recent essay collection About Us (Catapano and Garland-Thomson, 2019) is a useful starting point for nondisabled readers to build an understanding of various disability identities. The film Far from the Tree (Dretzin and Ephron, 2018), based on a book of the same name (Solomon, 2013), provides some additional first-person perspectives. An awareness of disability identities and the frameworks with which to address them may help enable genetics instructors to introduce relevant topics with empathy and respect, perhaps with an explicit acknowledgment of the complex relationship between the medical and social paradigms.

\section{Language Describing Phenotypes and Traits}

Careful language choices for defining and categorizing human phenotypes can also facilitate an inclusive and nonstigmatizing classroom environment. Textbooks and other sources typically use interchangeably the nouns "condition," "disease," "disorder," and "illness" without specifically defining any of them. Some sources equate "trait" with these terms, while others make a distinction between a "trait" and a "disease" to signal that not every human difference is a disease. What exactly differentiates a disorder/disease/illness/condition from other characteristics? In the field of psychiatry, professionals rely on the Diagnostic and Statistical Manual (DSM; American Psychiatric Association, 2013) as the official catalogue of what is considered a mental disorder and what is not. The National Human Genome Research Institute defines a genetic disorder as "a disease caused in whole or in part by a change in DNA sequence away from the normal sequence" (National Institutes of Health, 2018), without defining "disease" and providing only a short list of examples. The closest analogue to the DSM for geneticists is Online Mendelian Inheritance in Man, long billed as "an online catalogue of human genes and genetic disorders." The most recent published description of this resource (Amberger et al., 2019) notably adds language regarding its goal "to collect and curate knowledge on human genes and genetic disorders and traits [italics added]" compared with the previous version (Amberger et al., 2015). The individual entries in the database do not routinely indicate whether any given phenotype is officially considered a disorder or a trait, though some text descriptions do include one word or the other. For well-known single gene-associated phenotypes that directly affect health and quality of life, the terms "disease" and "disorder" are often used by people within those communities; however, for other wellknown genetic phenotypes like Down syndrome, the term "disorder" is not always welcomed (Canadian Down Syndrome Society, n.d.). Biology instructors aiming to be inclusive in the 
TABLE 2. Summary of recommendations for signaling inclusivity regarding disability

Remember that disabilities can be visible or invisible.

Always assume that disabled people may be present.

Do not single out a disabled person to share observations unless the person volunteers unprompted.

Know the complex interrelationship between the medical model and social model of disability and do not assume the medical model is always appropriate.

Use person-first language, but shift to identity-first when preferred by the individual/community.

Avoid stigmatizing terms like "abnormal," "disorder(ed)," and "disease(d)" in favor of more neutral terms like "affected," "atypical," "expresses trait," "variation," or "condition."

Avoid "mutant" in favor of "variant" when referring to human alleles and genotypes.

Avoid terms that emphasize pity, suffering, and overinspirationalizing, such as "victim," "afflicted," "suffer," "deficit," "defect," and "deformity."

classroom are advised to defer to language preferences among people in the relevant subset of the disability community, and when preferences vary or are not known, could potentially use neutral general nouns such as "trait," "variation," or "condition," instead of "disease" or "disorder" (Table 2). The adjectives "typical" and "atypical" are preferred to "normal" and "abnormal" when describing phenotypes, though "abnormal" is acceptable in some medical contexts (National Center on Disability and Journalism, n.d.). For cognitive or intellectual disabilities, "neurotypical" and "neuroatypical" are terms coming into wide use.

\section{Language Describing Alleles and Genotypes}

Geneticists routinely use "wild type" and "mutant" to differentiate alleles and genotypes, and sometimes as shorthand descriptors for whole individuals. Although this terminology seems unremarkable to people in the field, the term "mutant" to the general public has negative connotations as a result of wide usage in science fiction and popular culture. Even when "mutant" is employed to describe model organisms, the instructor could clarify that the word is a technical term with a different and more neutral meaning in the laboratory compared with what students may have encountered elsewhere. In discussions of human genetic traits, avoidance of the word "mutant" in favor of "variant" or another alternative could potentially minimize othering and stigmatizing disabled students.

\section{Language Describing Whole Individuals}

Students build empathy when reminded regularly that any study of genetic differences should encompass consideration and respect of the whole person. Using disabled persons' preferred terms for their identities is a key part of this respect. Ongoing debate within and beyond the disability community concerns whether person-first language (e.g., person with a disability, person with autism, person with dwarfism) or identity-first language (e.g., disabled person, autistic person, dwarf or little person) is more appropriate. Most style guides and professional societies recommend the person-first approach to centralize the humanity of the individual and to avoid defining the person primarily by the disability. Many members of the disability community instead prefer the identity-first approach to highlight that their disability is indeed a defining feature inextricable from their existence as persons (Ryan, 2018). Of course, when a particular person's preference is known, the most respectful approach is to use that person's desired descriptor. In the classroom, when referring to people not present, it can be hard to determine which framework is best, as connotations may vary for specific disabilities (e.g., person with epilepsy vs. epileptic, person with addiction vs. addict). Two psychology scholars give a cogent argument for flexibility (Dunn and Andrews, 2015), encouraging the person-first approach as an initial default but adopting the identity-first approach when it is known that a person or group aligns closely with a disability as an identity. In biology class, a similar flexibility seems warranted. Furthermore, explaining to students the reasons for terminology choices may enhance transparency and openness regarding awareness of disability issues.

Another context for describing whole individuals is in pedigree charts, which require defining the meaning of open or filled-in symbols for individual family members. Different textbooks employ terms such as "affected," "abnormal," "diseased," or "expresses trait" for filled-in symbols variously paired with "unaffected" or "normal" for open symbols (Pierce, 2016; Brooker, 2017; Hartl and Cochrane, 2017; Hartwell et al., 2017; Lewis, 2017). The "abnormal"-"normal" (or "diseased") framework is stigmatizing to disabled people; these terms are acceptable only in medical settings when referring to specific body parts or functions but not the person in general (National Center on Disability and Journalism, n.d.). Instructors are encouraged to adopt neutral definitions for filled-in pedigree symbols, such as "affected" or "expresses trait," or terms more specific to the exact context, such as "shows sickle cell anemia."

Biology courses with a focus on genetics sometimes employ case studies concerning genetic traits, highlighting individual people's experiences. Articles and media that illustrate the agency of disabled persons and that make clear their willingness and openness to share their story are more respectful to disabled people than pieces that tokenize, exoticize, or overinspirationalize the subject. Words like "victim," "afflicted," "suffer," "deficit," "defect," and "deformity," which inspire pity and minimize the person's agency, may be alienating; these terms imply a nondisabled "norm" and suggest that disabled people exist only as inspiration or edification to nondisabled people. A catchphrase within the disability community, "nothing about us without us," encapsulates the importance of intertwining first-person views, perceptions, and needs. Not only does this focus create a more inclusive environment for disabled students in the classroom, but such inclusion also sets the stage for pre-medical nondisabled genetics students to build awareness for future respectful interactions with disabled people, who often feel disenfranchised in clinical settings (Hogan et al., 2020). Table 2 summarizes recommendations for biology instructors to signal inclusivity regarding disability. 
A final thought regarding inclusion of disabled people in the classroom is that genetics instructors should acknowledge the troubling history of eugenics and its oppression of many groups, including disabled people (Micklos and Carlson, 2000). Eugenics and genetics were once intertwined fields. A genetics course is complete only with a perspective on eugenics and its consequences; this historical movement had vast ramifications with regard to disability, sexual orientation, gender identity, and race, the last of which is the focus of the next section.

\section{EXPLAINING THE ILLEGITIMACY OF PSEUDOSCIENTIFIC RACISM}

Stereotype threat from prejudices regarding differential intellectual ability among racial groups underlies a portion of the achievement gap between students of color and white students (Spencer et al., 2016). One cue that contributes to this effect is an instructor's adherence to a "fixed ability" mindset, the idea that intellectual capacity is inborn and unchangeable (Rattan et al., 2015; Canning et al., 2019). Mitigating stereotype threat, for example through promoting a "growth mindset," the idea that academic ability is malleable, is an important goal for better inclusivity and retention of students of color in all classrooms, regardless of topic. Stereotypes about racial differences in intellectual ability are also intrinsically based on misconceptions about genetic and biological differences among races. Genetics instructors are in a prime position to debunk the idea of biological race, thus undermining a key foundational pillar on which race-based ability stereotyping rests and setting the stage for lessening the impact of such stereotypes on all students.

The traditional approach in genetics courses-focusing primarily on monogenic traits-is problematic, in that it can increase students' misperceptions of racial biological differences, particularly when traits like sickle cell anemia are defined as varying in frequency between racial groups (Donovan, 2016, 2017). Here the idea of race is actually a rough and inaccurate proxy for ancestral populations (as discussed later), but students do not necessarily understand that, and they may mistakenly infer that there are broad, essential biological differences between races. Typical undergraduate genetics textbooks still relegate quantitative genetics and population/evolutionary genetics to stand-alone chapters at the end of the book (Pierce, 2016; Brooker, 2017; Hartl and Cochrane, 2017; Hartwell et al., 2017). A more modern approach, and one that would improve scientific literacy about human differences, is to integrate these topics earlier (Dougherty, 2009). The textbooks cited do not directly address how population and quantitative genetics relate to misperceptions about human racial differences, though one (Hartl and Cochrane, 2017) does end with a discussion of human adaptations like hemoglobinopathies and skin color; the final sentence, "Hence, similarity in skin color does not necessarily indicate genetic relatedness among individuals," is the closest foray into addressing race (p. 753). One human genetics textbook (Lewis, 2017) does indeed cover quantitative genetics early on, mentioning more explicitly the disconnect between biological populations and the sociocultural concept of race. At least one introductory biology textbook does the same (Campbell et al., 2018). Genetics instructors can add content and context depending on the textbook or other materials used.
Accurate framing of quantitative and population genetics demonstrably reduces racial bias even among high school students (Donovan et al., 2019). Various additional approaches for teaching about race and genetics in the biology classroom have measurable effects (Beckwith et al., 2017; Hubbard, 2017a,b). Thus, genetics instructors' choices have significant social impact. Although some instructors may feel discomfort including topics perceived as political, doing so is an important step toward inclusivity and retention of students from underrepresented groups. Refraining from addressing such topics is itself a political choice that reinforces the status quo. Genetics instructors are encouraged to build historical and cultural background knowledge and a language framework for discussing pseudoscientific racism.

Misapplication of genetics is at the heart of claims of race-based intellectual differences. Since the beginning of the European colonial era, white supremacists have co-opted scientific ideas to try to justify racial oppression and discrimination, an approach commonly termed "scientific racism"-though I use "pseudoscientific racism" to emphasize that the claims are not supported by science. The rediscovery of Mendel's work and subsequent focus on inheritance patterns during the early 20th century set the stage for the new field of genetics to be co-opted via the eugenics movement (Micklos and Carlson, 2000), in which the promotion of the "fittest" families was based on racist and ableist views, and the anti-immigration, anti-miscegenation, and forced sterilization laws included explicitly racist intentions. Even after Nazi atrocities seemed to discredit the idea of eugenics, misuse of science in the name of racism (and ableism and classism) has persisted to the present. Two wellknown, controversial books, The Bell Curve by a psychologist and political scientist (Herrnstein and Murray, 1994) and A Troublesome Inheritance by a science journalist (Wade, 2014) helped in recent decades to sustain misperceptions of racebased intellectual differences in intellectual ability. The latter book inspired 139 population geneticists to express in the New York Times that their work does not support Wade's claims (Coop et al., 2014.). James Watson, codiscoverer of the structure of DNA, is notorious for his repeated racist and sexist comments, which should be acknowledged alongside any mention of his achievements, lest the omission be construed as an endorsement. Instructors who seek a broader understanding of the history of pseudoscientific racism, particularly as it relates to genetics, will find useful resources in (among many other works) Angela Saini's Superior (Saini, 2019) and Robert Sussman's The Myth of Race (Sussman, 2014), both of which also highlight the surprising continued existence of funding sources pushing for the inclusion of racist work in academic literature. Misuse of genetic concepts by modern-day national politicians and white nationalists further underscores the persistence of pseudoscientific racist ideas and the importance of addressing them in genetics class.

A reconstrual intervention for reducing stereotype threat is to teach genetic reasons for the illegitimacy of racist claims regarding intelligence differences (Spencer et al., 2016). This approach does not necessarily require an explicit and condensed topical focus but can occur gradually as relevant concepts in population/evolutionary genetics and quantitative genetics arise. The previously mentioned books on the history of pseudoscientific racism (Sussman, 2014; Saini, 2019) along with 
articles for academic (Nisbett et al., 2012) and general (Evans, 2018) audiences review and summarize information that instructors can incorporate as appropriate to their course format; I briefly mention the main points here, though not as an exhaustive review.

With regard to population/evolutionary genetics, separating the sociocultural idea of race from the biological idea of populations is foundational. Over human history, as groups migrated around the world, populations intermingled and divided and intermingled again, in a way that can be imagined as a meshwork (Saini, 2019), with no clear separation between any large subsets of people. Building students' firm understanding of polymorphisms and allele frequencies in populations can set the stage for explaining the comparable breadth of genetic diversity within and between overlapping populations of humans. Crucial emphasis is on the fact that genetic profiles do not correlate with self-identified distinct races. Thus, there is no genetic/biological alignment with the sociocultural concept of race, though people are often fooled by loose association with a few features (skin color, sickle cell anemia) for which strong regional selection (sun exposure, pathogen prevalence) has had disproportionate effect. Biologists indeed carefully define the focus of genetic studies on "populations" not "races." Unfortunately, recent news media articles by scientists highlight that even the best intentions to distinguish "race" from "population" can, through the attempted use of irony with the word "race," have negative effects on public perception (Holmes, 2018; Reich, 2018).

Two topics further muddy the race/population confusion and require disentanglement for students. The expressed need for more diversity and inclusion in genomic studies and clinical trials (Bentley et al., 2017) reinforces the conflation of race with genetics, when instead race here is either a rough proxy for population diversity or a proxy for the downstream biological and health effects of racism and socioeconomic difference. The drug BiDil illustrates the conceptual dangers; approved by the FDA for treatment of congestive heart failure specifically in African Americans, BiDil is in reality not effective for a significant percentage of people with that identity and could in fact successfully treat many people of other racial identities, as a result of the wide genetic diversity across people of all groups (Saini, 2019). Divisions by genotype, and not by race, would allow for more successful use of this and other drugs. The second area contributing to race/population confusion is the growing interest in and availability of commercial genetic ancestry testing. Genetics instructors can help students distinguish that self-identified race is a separate concept from knowing the exact origin of all of one's ancestors, despite reports of people questioning identity after DNA testing (Lawton and Ifama, 2018).

Population genetics-based separation of sociocultural race from biological populations is thus one pillar for explaining the lack of validity of pseudoscientific racism. Another pillar is quantitative genetics, to demonstrate the complexity and many caveats of defining the basis of intelligence in the first place. With few specific common gene variants (out of thousands of genes connected to brain wiring) thus far associated with cognitive ability, and with results repeatedly showing the huge importance of environment and socioeconomic status on intelligence measurements, not to mention the difficulty of assessing the many facets of intelligence in an unbiased way (Nisbett et al., 2012), genetics instructors can help students understand the illegitimacy of attributing intelligence primarily to genetic makeup. In addition, because racial groups are not genetically distinct, any trace of genetic effect on intelligence that is separable from the large environmental effects will lead to similar variation within each group, not between groups. Collectively, the integration of population genetics and quantitative genetics topics throughout undergraduate genetics courses can set the stage for fruitful classroom coverage to debunk pseudoscientific racism, counteracting some of the prejudices that may otherwise trigger stereotype threat among students of color.

\section{RESPONSES FROM STUDENTS AND COLLEAGUES}

Undergraduate students in my courses have responded positively to recent intentional language shifts with regard to gender and disability, expressing appreciation verbally and on course evaluations for the efforts toward inclusivity. A subset of students readily adopted terms like "egg parent" and "sperm parent" into their written and oral vocabularies. For other students who did not demonstrate such a shift, it is not clear whether they were pushing back or were simply slower to adjust, especially because I acknowledged to students that I myself am still working toward consistency of language usage. There have been no explicitly negative responses. I aim to determine in the future whether students who have learned this terminology retain inclusive language choices long term. The approaches with regard to gender identity, disability, and race are applicable in some fields beyond genetics; colleagues not only in my department but also in other fields such as psychology who heard a presentation on these ideas have reported making relevant vocabulary changes in response to my suggestions.

\section{CONCLUSION}

Language choices regarding genetics topics in the biology classroom, combined with deliberate and nuanced framing of certain ideas, may enable instructors to foster a better sense of belonging among students of various identities who might otherwise feel alienated by the subject matter. Using phrases like "egg parent" and "sperm parent" instead of gendered language for biological parents in coverage of inheritance patterns has the potential to validate people of various gender identities, as does nongendered description of body parts. Nonstigmatizing terminology regarding genetic differences as they relate to disability may validate and include disabled students. Counteracting pseudoscientific racism through acknowledgment of the history of eugenics and careful coverage of population genetics and the basis of complex traits may mitigate aspects of racebased stereotype threat in the classroom. Setting an explicit tone of inclusion is likely to nudge other students planning to enter the biomedicine workforce to develop cultural competence and a more respectful approach toward human differences. Furthermore, students aiming for a wide range of other career paths, such as high school teaching, may similarly carry forward a broadened critical consciousness that will influence civic conversations and future generations. Instructors of genetics-related topics can thus promote topic-specific inclusive pedagogy. 


\section{ACKNOWLEDGMENTS}

Ann Fox, Barbara Lom, and two anonymous reviewers provided very helpful comments on the article. Members of the Spring 2018 and Spring 2019 BIO201 Genetics classes at Davidson College supplied meaningful feedback regarding some of these ideas. K.G.H. was supported by Davidson College and Davidson College's HHMI-funded Inclusive Excellence initiative.

\section{REFERENCES}

Amberger, J. S., Bocchini, C. A., Schiettecatte, F., Scott, A. F., \& Hamosh, A. (2015). OMIM.org: Online Mendelian Inheritance in Man (OMIM®), an online catalog of human genes and genetic disorders [Database issue]. Nucleic Acids Research, 43, D789-D798. https://doi.org/10.1093/nar/ gku1205

Amberger, J. S., Bocchini, C. A., Scott, A. F., \& Hamosh, A. (2019). OMIM.org: Leveraging knowledge across phenotype-gene relationships. Nucleic Acids Research, 47(D1), D1038-D1043. https://doi.org/10.1093/nar/ gky1151

American Psychiatric Association. (2013). Diagnostic and statistical manual of mental disorders: DSM-5 (5th ed.). Washington, DC: American Psychiatric Association.

Beckwith, J., Bergman, K., Carson, M., Doerr, T., Geller, L., Pierce, R., ... \& Zichterman, C. (2017). Using dialogues to explore genetics, ancestry, and race. American Biology Teacher, 79(7), 525-537. https://doi.org/10.1525/ abt.2017.79.7.525

Bennett, R. L., French, K. S., Resta, R. G., \& Doyle, D. L. (2008). Standardized human pedigree nomenclature: Update and assessment of the recommendations of the National Society of Genetic Counselors. Journal of Genetic Counseling, 17(5), 424-433. https://doi.org/10.1007/s10897008-9169-9

Bennett, R. L., Steinhaus, K. A., Uhrich, S. B., O'Sullivan, C. K., Resta, R. G., Lochner-Doyle, D., ... \& Hamanishi, J. (1995). Recommendations for standardized human pedigree nomenclature. American Journal of Human Genetics, 56(3), 745-752. https://doi.org/10.1007/BF01408073

Bentley, A. R., Callier, S., \& Rotimi, C. N. (2017). Diversity and inclusion in genomic research: Why the uneven progress? Journal of Community Genetics, 8(4), 255-266. https://doi.org/10.1007/s12687-017-0316-6

Brooker, R. J. (2017). Genetics: Analysis and principles (6th ed.). New York, NY: McGraw-Hill Education

Campbell, A. M., Heyer, L. J., \& Paradise, C. J. (2018). Integrating concepts in biology. Palo Alto, CA: Trunity.

Canadian Down Syndrome Society. (n.d.). What is Down syndrome? Retrieved June 21, 2019, from http://cdss.ca/down-syndrome-answers/ is-down-syndrome-a-disorder/

Canning, E. A., Muenks, K., Green, D. J., \& Murphy, M. C. (2019). STEM faculty who believe ability is fixed have larger racial achievement gaps and inspire less student motivation in their classes. Science Advances, 5(2), eaau4734. https://doi.org/10.1126/sciadv.aau4734

Case, K. A., Stewart, B., \& Tittsworth, J. (2009). Transgender across the curriculum: A psychology for inclusion. Teaching of Psychology, 36(2), 117-121.

Catapano, P., \& Garland-Thomson, R. (Eds.). (2019). About us: Essays from the disability series of the New York Times (1st ed.). New York, NY: Liveright.

Center for Disability Rights. (n.d.). Disability writing \& journalism guidelines. Retrieved June 13, 2019, from http://cdrnys.org/disability-writing -journalism-guidelines

Coop, G., et al. (2014, August 8). Letters: "A Troublesome Inheritance." New York Times. Retrieved June 24, 2019, from www.nytimes.com/2014/ 08/10/books/review/letters-a-troublesome-inheritance.html

Cyranoski, D., \& Ledford, H. (2018). Genome-edited baby claim provokes international outcry. Nature, 563(7733), 607-608. https://doi.org/10.1038/ d41586-018-07545-0

Dewsbury, B., \& Brame, C. J. (2019). Inclusive teaching. CBE-Life Sciences Education, 18(2), fe2. https://doi.org/10.1187/cbe.19-01-0021

Donovan, B. M. (2016). Framing the genetics curriculum for social justice: An experimental exploration of how the biology curriculum influences beliefs about racial difference. Science Education, 100(3), 586-616. https:// doi.org/10.1002/sce.21221
Donovan, B. M. (2017). Learned inequality: Racial labels in the biology curriculum can affect the development of racial prejudice. Journal of Research in Science Teaching, 54(3), 379-411. https://doi.org/10.1002/tea.21370

Donovan, B. M., Semmens, R., Keck, P., Brimhall, E., Busch, K. C., Weindling, M., ... \& Salazar, B. (2019). Toward a more humane genetics education: Learning about the social and quantitative complexities of human genetic variation research could reduce racial bias in adolescent and adult populations. Science Education, 103(3), 529-560. https://doi.org/ $10.1002 /$ sce. 21506

Dougherty, M. J. (2009). Closing the gap: Inverting the genetics curriculum to ensure an informed public. American Journal of Human Genetics, 85(1), 6-12. https://doi.org/10.1016/j.ajhg.2009.05.010

Dretzin, R., \& Ephron, J. (2018). Far from the tree. New York: IFC Films Retrieved December 18, 2019, from www.imdb.com/title/tt6848736/

Dunn, D. S., \& Andrews, E. E. (2015). Person-first and identity-first language: Developing psychologists' cultural competence using disability language. American Psychologist, 70(3), 255-264. https://doi.org/10.1037/ a0038636

Estrada, M., Young, G. R., Nagy, J., Goldstein, E. J., Ben-Zeev, A., MárquezMagaña, L., \& Eroy-Reveles, A. (2019). The influence of microaffirmations on undergraduate persistence in science career pathways. CBE-Life Sciences Education, 18(3), ar40. https://doi.org/10.1187/cbe.19-01-0012

Evans, G. (2018, March 2). The unwelcome revival of "race science." The Guardian. Retrieved June 24, 2019, from www.theguardian.com/ news/2018/mar/02/the-unwelcome-revival-of-race-science

Harrison, C., \& Tanner, K. D. (2018). Language matters: Considering microaggressions in science. CBE-Life Sciences Education, 17(1), fe4. https:// doi.org/10.1187/cbe.18-01-0011

Hartl, D. L., \& Cochrane, B. (2017). Genetics: Analysis of genes and genomes (9th ed.). Burlington, MA: Jones \& Bartlett Learning.

Hartwell, L., Goldberg, M. L., Fischer, J., \& Hood, L. (2017). Genetics: From genes to genomes (6th ed.). New York, NY: McGraw-Hill Education.

Herrnstein, R. J., \& Murray, C. (1994). The bell curve: Intelligence and class structure in American life. New York, NY: Free Press.

Higher Education Research Institute. (2011). College students with "hidden" disabilities. Los Angeles: University of California. Retrieved December 18 2019, from www.heri.ucla.edu/PDFs/pubs/briefs/HERI_ResearchBrief _Disabilities_2011_April_25v2.pdf

Hogan, A., Jain, N. R., Peiris-John, R., \& Ameratunga, S. (2020). Disabled people say "Nothing about us without us." Clinical Teacher, 17(1), 70-75. https://doi.org/10.1111/tct.13022

Holmes, I. (2018, April 25). What happens when geneticists talk sloppily about race. The Atlantic. Retrieved June 10, 2019, from www.theatlantic .com/science/archive/2018/04/reich-genetics-racism/558818

Hubbard, A. R. (2017a). Teaching race (bioculturally) matters: A visual approach for college biology courses. American Biology Teacher, 79(7) 516-524. https://doi.org/10.1525/abt.2017.79.7.516

Hubbard, A. R. (2017b). Testing common misconceptions about the nature of human racial variation. American Biology Teacher, 79(7), 538-543. https://doi.org/10.1525/abt.2017.79.7.538

Kang, E., Wu, J., Gutierrez, N. M., Koski, A., Tippner-Hedges, R., Agaronyan, K., \& Mitalipov, S. (2016). Mitochondrial replacement in human oocytes carrying pathogenic mitochondrial DNA mutations. Nature, 540(7632) 270-275. https://doi.org/10.1038/nature20592

Kapitan, A. (2017, September 12). Update to transgender style guide: Bodies and anatomy. Radical Copyeditor. Retrieved June 5, 2019, from https:// radicalcopyeditor.com/2017/09/12/update-to-transgender-style -guide-bodies-and-anatomy

Lawton, G., \& Ifama, D. (2018, August 11). "It made me question my ancestry": Does DNA home testing really understand race? The Guardian. Retrieved June 26, 2019, from www.theguardian.com/lifeandstyle/2018/aug/11/ question-ancestry-does-dna-testing-really-understand-race

Lewis, R. (2017). Human genetics (12th ed.). New York, NY: McGraw Hill Higher Education.

Linton, S. (1998). Claiming disability: Knowledge and identity. New York, NY: NYU Press.

Micklos, D., \& Carlson, E. (2000). Engineering American society: The lesson of eugenics. Nature Reviews Genetics, 1(2), 153-158. https://doi. org/10.1038/35038589 
National Center on Disability and Journalism. (n.d.). Disability language style guide. Retrieved June 6, 2019, from https://ncdj.org/style-guide

National Institutes of Health. (2018). Genetic disorders. Retrieved June 21, 2019, from www.genome.gov/For-Patients-and-Families/Genetic-Disorders

Nielsen, K. E. (2012). A disability history of the United States. Boston, MA: Beacon Press.

Nisbett, R. E., Aronson, J., Blair, C., Dickens, W., Flynn, J., Halpern, D. F., \& Turkheimer, E. (2012). Intelligence: New findings and theoretical developments. American Psychologist, 67(2), 130-159. https://doi. org/10.1037/a0026699

Pierce, B. A. (2016). Genetics: A conceptual approach (6th ed.). New York, NY: W. H. Freeman.

Rattan, A., Savani, K., Chugh, D., \& Dweck, C. S. (2015). Leveraging mindsets to promote academic achievement: Policy recommendations. Perspectives on Psychological Science, 10(6), 721-726. https://doi.org/ 10.1177/1745691615599383

Reich, D. (2018, April 1). Opinion: How Genetics Is Changing Our Understanding of "Race." New York Times. Retrieved June 10, 2019, from www .nytimes.com/2018/03/23/opinion/sunday/genetics-race.html

Ryan, M. (2018). I don't have autism. I'm autistic. Lenny. Retrieved June 19 2019, from www.lennyletter.com/story/i-dont-have-autism-im-autistic

Saini, A. (2019). Superior: The return of race science. Boston, MA: Beacon Press.

Schinske, J. N., Perkins, H., Snyder, A., \& Wyer, M. (2016). Scientist spotlight homework assignments shift students' stereotypes of scientists and enhance science identity in a diverse introductory science class. CBE-Life Sciences Education, 15(3), ar47. https://doi.org/10.1187/cbe.16-01-0002

Seidel, S. B., Reggi, A. L., Schinske, J. N., Burrus, L. W., \& Tanner, K. D. (2015) Beyond the biology: A systematic investigation of noncontent instructor talk in an introductory biology course. CBE-Life Sciences Education, 14(4), ar43. https://doi.org/10.1187/cbe.15-03-0049

Snyder, T. D., deBrey, C., \& Dillow, S. A. (2019). Digest of education statistics 2017 (NCES 2018-070). Washington, DC: National Center for Education Statistics, Institute of Education Sciences, U.S. Department of Education.

Solomon, A. (2013). Far from the tree: Parents, children and the search for identity (Reprint ed.). New York: Scribner.

Spade, D. (2011). Some very basic tips for making higher education more accessible to trans students and rethinking how we talk about gendered bodies. Radical Teacher, 92(1), 57-62.

Spencer, S. J., Logel, C., \& Davies, P. G. (2016). Stereotype threat. Annual Review of Psychology, 67, 415-437. https://doi.org/10.1146/ annurev-psych-073115-103235

Stroumsa, D., Roberts, E. F. S., Kinnear, H., \& Harris, L. H. (2019). The power and limits of classification-a 32-year-old man with abdominal pain. New England Journal of Medicine, 380(20), 1885-1888. https://doi .org/10.1056/NEJMp1811491

Sussman, R. W. (2014). The myth of race: The troubling persistence of an unscientific idea. Cambridge, MA: Harvard University Press. Retrieved June 25, 2019, from www.jstor.org/stable/j.ctt9qdt73

Taneja, P. R., Pandya, A., Foley, D. L., Nicely, L. V., \& Arnos, K. S. (2004). Attitudes of deaf individuals towards genetic testing. American Journal of Medical Genetics. Part A, 130A(1), 17-21. https://doi.org/10.1002/ajmg.a.30051

Tanner, K. D. (2013). Structure matters: Twenty-one teaching strategies to promote student engagement and cultivate classroom equity. CBELife Sciences Education, 12(3), 322-331. https://doi.org/10.1187/ cbe.13-06-0115

Wade, N. (2014). A troublesome inheritance: Genes, race and human history New York, NY: Penguin Press. 